\title{
A educação como direito coletivo na construção da cidadania e dignidade da pessoa humana: a realidade de um estado de coisas inconstitucional
}

\author{
Maria Cristina Vidotte Blanco Tárrega ${ }^{1}$ \\ Felipe Freitas de Araújo Alves ${ }^{2}$ \\ Ana Patricia Ribeiro Approbato ${ }^{3}$
}

\begin{abstract}
RESUMO
A Constituição Cidadã de 1988, além de ser um marco histórico na construção do Estado Democrático de Direito, priorizou os direitos e garantias fundamentais. Entre estes, estão elencados os denominados direitos sociais pertencentes à segunda dimensão de direitos humanos. Integrando os direitos sociais encontra-se a educação como base para a construção de uma consciência que preza pela dignidade da pessoa humana e o efetivo exercício da cidadania, dois fundamentos do Estado Democrático de Direito. Assim, fazse mister a compreensão dos conceitos de cidadania e de dignidade da pessoa humana, temas abarcados pelos direitos humanos. Após tal compreensão, a educação é apontada como direito social fundamental em seus aspectos constitucionais e infraconstitucionais. Ocorre que, a falta de apreço do Poder Público para com esse direito social fundamental causa uma situação insustentável, generalizada, um verdadeiro estado de coisas inconstitucional. Neste viés, surge a necessidade de o Poder Judiciário, respeitando a autonomia dos Poderes Executivo e Legislativo, agir em prol da harmonia e com a equidade que lhe é exigida, suscitar a concreção daquilo que é dever do Poder Público, o que no presente ensaio é o direito social fundamental à educação. O método de pesquisa é bibliográfico, descritivo e qualitativo, partese do confronto entre as bibliografias para se descrever os resultados. Após, a
\end{abstract}

\footnotetext{
${ }^{1}$ Doutora em Direito pela Pontíficia Universidade Católica de São Paulo/SP. Orcid. https://orcid.org/0000-0002-48054345.E-mail: mcvidotte@uol.com.br.

${ }^{2}$ Mestre em Direito pela Universidade de Ribeirão Preto/SP. Orcid. http://orcid.org/0000-0002-5844-0485. E-mail: felipe.jhs@hotmail.com.

3 Mestranda da Universidade de Ribeirão Preto/SP. Orcid. https://orcid.org/0000-0001-6473-0289. E-mail: patricia.apra@gmail.com.
} 
análise infere-se que, embora pouco utilizado no ordenamento pátrio, o país vive na Educação um autêntico Estado de coisas inconstitucional.

PALAVRAS-CHAVE: Cidadania. Dignidade da Pessoa Humana. Direitos Humanos. Educação. Estado de coisas inconstitucional.

Education as a collective right in the construction of citizenship and dignity of the human person: the reality of an unconstitutional state of things

\begin{abstract}
The Citizen Constitution of 1988 is a historical mark for the construction of the Democratic State of Law and it prioritized fundamental rights and guarantees. Within these, are the so-called social rights from the second generation of human rights. Education integrates social rights and is the basis for building a conscience that values the dignity of the human person and the effective exercise of citizenship, two cornerstones of the Democratic State of Law. Thus, it is necessary to comprehend the concept of citizenship and the dignity of the human person, issues embraced by human rights. After this comprehension, education will be identified as a fundamental social right with its constitutional and infra-constitutional aspects. The fact is that the lack of public appreciation of this fundamental social right causes a generalized unsustainable situation; a true unconstitutional state of things). Therefore, while respecting the autonomy of the Executive and the Legislative Branches, the need for the Judiciary to act in favor of harmony and with the equity it portrays arises, as well as, the need for the Judiciary to evoke Public Authorities to fulfill their obligations. In the present paper, this translates as the fundamental social right to education.
\end{abstract}

KEYWORDS: Citizenship. Dignity of the Human Person. Human Rights. Education. Unconstitutional state of things.

La educación como derecho colectivo en la construcción de la ciudadanía y la dignidad de la persona humana: la realidad de un estado de cosas inconstitucional

\title{
RESUMEN
}

La Constitución Ciudadana de 1988, además de ser un hito histórico en la construcción del Estado de Derecho Democrático, priorizó los derechos y garantías fundamentales. Entre estos, se enumeran los 
llamados derechos sociales que pertenecen a la segunda dimensión de los derechos humanos. La integración de los derechos sociales es la educación como base para construir una conciencia que valore la dignidad de la persona humana y el ejercicio efectivo de la ciudadanía, dos fundamentos del Estado de derecho democrático. Por lo tanto, es esencial comprender los conceptos de ciudadanía y dignidad humana, temas cubiertos por los derechos humanos. Después de tal comprensión, la educación se identifica como un derecho social fundamental en sus aspectos constitucionales e infraconstitucionales. Resulta que la falta de apreciación del Poder Público por este derecho social fundamental provoca una situación insostenible y generalizada, un verdadero estado de cosas inconstitucional. En este sentido, surge la necesidad de que el Poder Judicial, respetando la autonomía de los poderes ejecutivo y legislativo, actúe a favor de la armonía y con la equidad que se le exige, para concretar lo que es el deber del Poder Público, que en este ensayo Es el derecho social fundamental a la educación. El método de investigación es bibliográfico, descriptivo y cualitativo, comenzando por la comparación entre las bibliografías para describir los resultados. Posteriormente, el análisis implica que, aunque poco utilizado en el orden nacional, el país vive en la educación un auténtico estado inconstitucional.

PALABRAS ClAVE: Ciudadanía. Dignidad de la persona humana. Derechos humanos. Educación. Estado de cosas inconstitucional.

\author{
$* * *$ \\ "Ensinar não é transferir conhecimento, mas criar as possibilidades para a sua \\ própria produção ou a sua construção". \\ Paulo Freire
}

\title{
Introdução
}

Com o advento da Constituição de 1988, a denominada Constituição Cidadã, a educação adquiriu status de direito fundamental de caráter social. A previsão constitucional está normatizada no artigo $6^{\circ}$ e 
detalhada no Título VIII - Da Ordem Social - notadamente entre os artigos 205 e 214 da Lei maior.

Além da previsão constitucional, no ordenamento pátrio existem leis e planos que regulamentam a matéria4. Ocorre que, apesar de ampla a legislação, o direito fundamental social à educação vem sendo desrespeitado e, consequentemente, por se tratar de direito que contribui para a formação da mentalidade crítica em crianças, adolescente jovens, adultos e idosos, são violados, principalmente, dois fundamentos do Estado Democrático de Direito: a cidadania e a dignidade da pessoa humana ${ }^{5}$.

A falta de uma educação de qualidade contribui para formação de cidadãos não instruídos, corroborando para que a vida digna seja aquém. A educação é o instrumento constitucional que abre a mente para compreensão do verdadeiro significado do Estado Democrático de Direito.

Ocorre que, diante da omissão do Estado se faz necessária a atuação do Poder Judiciário através do Estado de coisas inconstitucional para efetivação daquilo que é garantido pela Lei Maior e, também, por leis infraconstitucionais.

Dessa forma, o presente ensaio ficou tem por objetivos abordar acerca da cidadania e da dignidade da pessoa humana como fundamentos do Estado Democrático de Direito, o direito social fundamental à educação e, por fim, discutir o estado de coisas inconstitucional.

A pesquisa foi realizada a partir da legislação pátria, da doutrina, de pesquisadores nas mais diversas áreas da ciência humana. Utilizou-se o método dedutivo, onde prevalece a racionalização e combinação de ideias. O raciocínio esforça-se por um caráter lógico, inferencial e divergente, pois se fundamenta naquilo que está positivado; aborda uma perspectiva implícita nos autores pesquisados e na própria legislação e

\footnotetext{
${ }^{4}$ BRASIL. Lei de Diretrizes e Bases da Educação Nacional (Lei no 9.394/96); o Estatuto da Criança e do Adolescente (Lei n ${ }^{\circ}$ 8.069/90); o Plano Nacional de Educação (Lei ${ }^{\circ}{ }^{10.172 / 2001)}$; Estatuto do Idoso (Lei n ${ }^{\circ} 10.741 / 2003$ ).

${ }^{5}$ BRASIL. Constituição Federal. Artigo $1^{\circ}$, incisos II e III.
} 
apresenta uma possível solução, embora nova no ordenamento jurídico pátrio, para a concreção do direito social à educação.

O trabalho visa a levantar uma crítica sobre a importância do direito social fundamental à educação como premissa base para a construção de uma sociedade mais digna e cidadã, mesmo que para isso seja necessário uma atuação mais ativista do Poder Judiciário.

A temática aqui apresentada não é um findar do tema, ao contrário, é apenas um germe para que o povo brasileiro possa desfrutar de seus direitos e não somente ser um mero cumpridor de deveres.

\section{Cidadania e dignidade da pessoa humana: fundamentos do estado democrático de direito}

A democracia como modelo político que remonta à idade antiga (Grécia) e chega aos dias atuais com nova configuração. Existe uma ligação intrínseca entre democracia e cidadania. A cidadania é fundamento do Estado Democrático de Direito. Assim, o entendimento do termo democrático implica dentro do Estado Democrático de Direito na criação de leis pelos cidadãos e para estes, respeitada a dignidade da pessoa humana. ${ }^{6}$

Em duas obras de Aristóteles, quais sejam, "A Ética a Nicômaco" e "A política", verifica-se uma visão da situação concreta existencial do homem grego. Na primeira encontra-se a ordenação dos atos da vontade em vista do bem supremo que é a felicidade (ARISTÓTELES, 1979, p 49); na segunda expõe-se a organização civil grega.

$\mathrm{Na}$ "Ética" o Estagirita demonstrou como o homem pode conseguir nesta vida a felicidade por meio das virtudes. Estas são hábitos que cada um constrói, mas que têm a característica essencial da denominada "justa medida”. A justa medida é o caminho intermediário entre extremos, seja a

\footnotetext{
${ }^{6}$ BRASIL. Entenda o que é o Estado Democrático de Direito. Publicado: 30/10/2018 15h38. Especialista explica as origens desse conceito, que define o Estado brasileiro e suas características. Disponível em: http://www2.planalto.gov.br/mandatomicheltemer/acompanhe-planalto/noticias/2018/10/entenda-o-que-eo-estado-democratico-de-direito. Acesso em: 27 de set. de 2020.
} 
tendência ao excesso ou à falta. ${ }^{7}$ Assim, dentre todas as virtudes a justiça é a que possui maior destaque, pois é fundamento da própria sociedade.

$\mathrm{Na}$ "Política", Aristóteles aborda a Pólis - Cidade Estado - que segundo sua visão precede as partes, isto é, a cidade é anterior aos indivíduos que dela fazem partes. E é na cidade que os indivíduos adquirem a identidade de cidadãos que se reunirão na "Ágora" para resolver as questões concernentes à própria política.

Assim, em Aristóteles Ética e Política se completam, a primeira em um nível particular e a segunda como atividade estatal. E como ocorre tal complementação? Por meio da justiça. É através da justiça, a maior virtude, que o particular sente-se na obrigação de realizar ações leais aos outros, sejam governantes ou aos concidadãos. Dessa forma, a justiça é o "bem do outro".

Mas a justiça também possui acepção que faz referência estrita à cidade: lugar de associação de homens iguais; sendo a igualdade um princípio norteador (ARISTÓTELES, 1979, p. 121-123) A essa justiça Aristóteles dá o nome de distributiva, pois diz respeito à reta distribuição, por parte do Estado, aos seus cidadãos. E de outro lado, refere-se à imposição das penas aos transgressores da lei.

Hodiernamente, a ideia de democracia deve trabalhar de maneira prática e com resultados concretos. Aquilo que foi teorizado pelos gregos, relacionados ao bem de todos, deve perfazer todo caminho democrático no que diz respeito à igualdade, dignidade, acesso de todas as pessoas à educação etc.

O conceito de cidadania ampliou-se com o pensamento do sociólogo Thomas Humphrey Marshall. Segundo este autor, a ideia de cidadania é composta de três elementos normativos, sendo eles, elemento civil, elemento político e elemento social (MOURA, 2010, p 24).

De acordo com Marshall (MASTRODI, 2017), no ocidente europeu, no século XVIII, surgem as condições históricas que levaram à conquista da

\footnotetext{
${ }^{7}$ Para exemplificar: "a coragem, por exemplo, é o caminho intermédio entre a temeridade e a timidez, e a liberalidade é o justo meio entre a prodigalidade e a avareza" (REALE, 2003, pp. 219-220).
} 
cidadania civil, onde os cidadãos, ao menos em tese, podiam lutar, ao menos enquanto possibilidade, por seus direitos na esfera individual.

Posteriormente, no século XIX surge o período da cidadania política onde observa-se não só a criação de direitos políticos, mas a ampliação dos direitos civis de outrora. Neste elemento de cidadania política aponta o sociólogo "começando do ponto no qual todos os homens eram livres, em teoria, capazes de gozar de direitos, a cidadania se desenvolveu pelo enriquecimento do conjunto de direitos de que eram capazes de gozar" (MARSHALL, 2002, p. 27). Finalmente, no século XX surge a cidadania social com o reconhecimento mínimo de sobrevivência, como o direito à saúde e à educação. Neste ponto, cabe uma ressalva: embora exista a aparência de semelhança entre a teoria do sociólogo e a teoria das gerações dos direitos humanos, deve-se salientar que são perspectivas diferentes. Observe-se que Marshall não teceu comentário sobre os direitos difusos presentes naquilo que convencionou-se chamar terceira dimensão de direitos humanos.

Todavia, é a partir da universalização dos direitos fundamentais e da ampliação da cidadania na esfera social e econômica (direitos sociais, coletivos e difusos) que se verifica o grande avanço na implantação do Estado Democrático.

A Carta Magna, em seu preâmbulo faz menção ao Estado Democrático de Direito com um objetivo assecuratório de direitos sociais e individuais entre outros (BRASIL, 1988).

A própria a realidade mostra aos cidadãos que os direitos mencionados não são garantidos. A própria Constituição contempla o projeto de Estado Democrático de Direito a ser perseguido e conquistado. Para tanto, basta ver que o conceito de cidadania é limitado, pela sociedade em geral, ao simples fato de ser eleitor. Parecendo que somente por meio do voto que o cidadão exerce sua cidadania.

A Secretaria da Justiça, Trabalho e Direitos Humanos do Estado do Paraná, por meio do Departamento de Direitos Humanos e Cidadania (DEDIHC) define o cidadão como sujeito que tem direitos, sejam estes de caráter civil, político e social (PARANÁ, 2019). Dessa forma, a expressão concreta de 
exercer a democracia se dá na cidadania plena e nos seu exercício de direitos (PARANÁ, 2019). Apesar de louvável os termos utilizados para definir a cidadania e a maneira de exercê-las, infelizmente, ainda resta um longo caminho a ser percorrido para sua concreção e de seu respectivo exercício.

Complementando, acrescente-se a noção de democracia deliberativa de Jürgen Habermas (2003, p. 354). Para o filósofo o modelo de democracia deliberativa privilegia a dimensão cidadã como uma espécie de ligação entre a dimensão individual e a dimensão cultural. Assim, todas as pessoas são sujeitos ativos na construção da identidade política por um patriotismo constitucional que se configura na decisão das normas e valores para toda a comunidade que, sendo plural, está sob a égide da Constituição. Por isso, Habermas tem a ideia de cidadania ligada à condição ativa da pessoa humana em suas esfera individual e cultural.

\section{Dignidade da pessoa humana}

A noção de dignidade da pessoa humana não é única. Suas variantes comportam análises diversas. De acordo com Ramos, "os direitos humanos consistem em um conjunto de direitos considerado indispensável para uma vida humana pautada na liberdade, igualdade e dignidade. Os direitos humanos são os direitos essenciais e indispensáveis à vida digna” (RAMOS, 2018, p. 28) (Grifo nosso).

A pessoa humana é o sujeito dos direitos humanos. Logo, é importante distinguir o conceito pessoa do conceito de indivíduos. O indivíduo é "aquilo que não pode ser dividido. (BOÉCIO apud ABBAGNANO, 2007, p. 555). Assim, o conceito de indivíduo é mais interno e indivisível ${ }^{8}$ do que a concepção de pessoa. O conceito de pessoa volta-se à esfera relacional, seja com o outro, com o mundo, com os seres que a rodeiam. Hodiernamente o conceito de pessoa preceitua "cada ser

\footnotetext{
${ }^{8}$ Neste caso o homem é entendido como um único ser, embora possa ser desmembrado, não se transforma em vários outros seres.
} 
humano como pessoa única, sujeito de direitos e deveres, com uma dignidade e valor intrínsecos" (DIEHL, 2018, p. 39). Tal definição é adotada pela Declaração Universal de direitos Humanos de 1948 (DUDH). Assim, a ideia de direitos humanos, de forma geral, pressupõe que existem direitos próprios do ser humano e intrínsecos a ele, em virtude de sua particular dignidade. Assim, os direitos humanos configuram-se como normas ou princípios universais que se aplicam a todos os seres humanos, independente de etnia, nacionalidade, convicção política, sexo ou outras características ${ }^{9}$.

Em seus trinta artigos, a Declaração Universal dos Direitos Humanos pontua, de forma sintética, os denominados direitos civis, políticos, sociais, econômicos e culturais, todos permeados da ideia de dignidade já apontada no artigo I do citado documento: "todos os seres humanos nascem livres e iguais em dignidade e direitos. São dotados de razão e consciência e devem agir em relação uns aos outros com espírito de fraternidade" (Grifo nosso).

Sobrevém que para chegar a tal compreensão os direitos humanos passaram por uma espécie de "evolução", o que na doutrina conceituou como "dimensões" ou "gerações". A doutrina majoritária tem preferido a utilização do termo "dimensões" em vez de "gerações" para não ocorrer uma interpretação equivocada, em que o termo "geração" poderia ser interpretado de forma excludente; ao contrário do termo "dimensões" que sugere inclusão, ampliação. Apesar da controvérsia terminológica, pode-se apresentar as gerações de direitos humanos da seguinte forma: a primeira geração engloba os direitos civis e políticos, a segunda os direitos sócias, a terceira os direitos transindividuais e por fim o direito dos povos (TRINDADE JÚNIOR, 2015, p. 19). Dessa forma, a educação faz parte da segunda dimensão dos direitos fundamentais, sendo direito fundamental social que objetiva a realização da Justiça na ordem social e exige uma atuação direta, ou seja, um fazer por parte do Poder Público. Porém, como será abordado adiante, o Estado tem

\footnotetext{
${ }^{9}$ Conforme expresso nos artigos $1^{\circ}$ e $2^{\circ}$ da DUDH, 1948.
} 
sido omisso em relação aos direitos sociais, deixando em segundo plano a educação, cerne da formação de pessoas com consciência cidadã.

Antes de adentrar na temática da educação como direito social fundamental, é necessário frisar que os direitos fundamentais, independente da dimensão que façam parte, possuem características que lhes são inerentes, quais sejam, historicidade, universalidade, inexauribilidade, essencialidade, imprescritibilidade, inalienabilidade, irrenunciabilidade, inviolabilidade, efetividade, limitabilidade, complementariedade, concorrência e vedação ao retrocesso (PENTEADO FILHO, 2012, pp. 23-24) (Grifo nosso). Não obstante as características estejam intimamente relacionadas, destacou-se a efetividade por se tratar de um dever de a Administração Pública criar mecanismos coercitivos capazes de efetivar tais direitos. Entre esses instrumentos será apresentado ao final deste ensaio o Estado de coisas inconstitucional (ECI), recentemente adotado pelo Supremo Tribunal Federal (STF) na Arguição de Descumprimento de Preceito Fundamental (ADPF) número 347 - Distrito Federal.

\section{Direito fundamental à educação}

O direito fundamental à educação é espécie de direito social e está previsto no artigo $6^{\circ}$ da Constituição Federal de 1988. Por se tratar de direito fundamental, a educação é de suma importância para a concretização de um Estado Social e Democrático de Direito, ideia já proposta no preâmbulo constitucional. Ao valorizar a educação como direito social, em tese, o Estado faz um papel prestacional, que impõe a si mesmo o dever de agir para concreção direta e imediata de tal interesse. ${ }^{10}$

De acordo com o jurista e escritor brasileiro Fábio Konder os direitos sociais "se realizam pela execução de políticas públicas, destinadas a garantir amparo e proteção social aos mais fracos e mais pobres; ou seja, aqueles que não dispõem de recursos próprios para viver dignamente" (COPARATO, 2010, p. 77). Neste viés, surge a espécie de

\footnotetext{
${ }^{10} \mathrm{O}$ dever prestacional Estatal está ligado à todos os direitos sociais, não só à educação.
} 
direito-pretensão11 que exige de um terceiro, seja este o Estado ou particular, uma conduta garantidora de tal pretensão.

"No âmbito desse Estado, de caráter prestacional, a positivação jurídica de valores sociais passou a servir de base não apenas à interpretação de toda a Constituição, mas à criação, direção e regulação de situações concretas." (DUARTE, 2007, p. 694)

É justamente nesta esfera de direito-pretensão que a educação aparece normatizada no artigo 208, inciso I, da Constituição Federal de 1988. A própria proclamação da Declaração Universal dos Direitos Humanos (1948) como ideal comum a todos o esforço em "através do ensino e da educação, por promover respeito a esses direitos e liberdades, e, pela adoção de medidas progressivas de caráter nacional e internacional, por assegurar o seu reconhecimento a sua observância universal e efetiva [...]". Mais uma vez, a educação é apontada como base para construção de uma sociedade democrática.

No ordenamento jurídico pátrio, além da previsão constitucional acerca do direito social à educação e da Declaração Universal dos Direitos Humanos $^{12}$, existe também a Lei de Diretrizes e Bases da Educação Nacional - Lei n ${ }^{\circ}$ 9.394/96 - (LDB); o Estatuto da Criança e do Adolescente - Lei no 8.069/90 - (ECA); o Plano Nacional de Educação - Lei n ${ }^{\circ}$ 10.172/2001 - (PNE) e o Estatuto do Idoso - Lei n 10.741/2003.

Ao se analisar a LDB observa-se que ao estabelecer diretrizes que regulamentam a educação, o foco se dá na própria dignidade da pessoa humana. Assim se extrai do artigo $1^{\circ}$ do citado documento, in verbis: "a educação abrange os processos formativos que se desenvolvem na vida familiar, na convivência humanam no trabalho, nas instituições de ensino e pesquisa, nos movimentos sociais e organização da sociedade civil e nas manifestações culturais" (BRASIL, 1996).

\footnotetext{
11 Saliente-se que entre a estrutura dos direitos humanos também existe, além do direito-pretensão, o direito-liberdade; o direito-poder e o direito-imunidade. Estes não são abordados no presente ensaio por não estarem vinculados de forma direta ao tema.

${ }^{12}$ No Brasil tal declaração possui status normativo supralegal conforme entendimento do STF, pois ainda não foi votada conforme a previsão do artigo $5^{\circ}, \S 3^{\circ}$, da CF/88.
} 
Desta afirmação, pode-se inferir que a Educação é o próprio processo formativo que perpassa a vida humana (dignidade) e social (cidadania). A educação é o método existente para a configuração de algo, ou seja, é o método que abrange o indivíduo e a pessoa, esta na esfera relacional, aquele na esfera íntima.

Neste sentido Moacir Alves Carneiro comentando o artigo $1^{\circ}$ da LDB, afirma a existência de ruptura axiológica ao apontar a educação como atributo coletivo (CARNEIRO, 2013, p. 38). Desta forma, o autor supramencionado amplia o conceito de educação não o restringindo a apenas a instituições sociais de ensino mas levanta a hipótese de uma mudança valorativa da educação ao pensar sua importância a partir do desenvolvimento humano.

A própria LDB afirma do parágrafo $1^{\circ}$, artigo $1^{\circ}$, que "este lei disciplina a educação escolar, que se desenvolve, predominantemente, por meio do ensino, em instituições próprias, mas não exclusivamente nelas" (Grifo nosso). Prosseguindo, o parágrafo $2^{\circ}$ do mesmo artigo estabelece que "a educação escolar deverá vincular-se ao mundo do trabalho e à prática social”, isto é, a educação é fator intrínseco para a concreção da cidadania e da dignidade da pessoa humana.

O artigo 205 da Constituição Federal positiva que: "A educação, direito de todos e dever do Estado e da família, será promovida e incentivada com a colaboração da sociedade, visando ao pleno desenvolvimento da pessoa $^{13}$, seu preparo para o exercício da cidadania e sua qualificação para o trabalho" (Grifo nosso). Em consonância com tal previsão, o artigo $1^{\circ}$ da LDB prescreve "a educação, dever da família e do Estado, inspirada nos princípios de liberdade e nos ideias de solidariedade humana, tem por finalidade $o$ pleno desenvolvimento do educando, seu preparo para o exercício da cidadania e sua qualificação para o trabalho Comentando o tema, Carneiro afirma que a finalidade da educação está caracterizada em vista dos cidadãos que a mesma pretende formar (CARNEIRO, 2013, p.43).

A educação possui uma função-finalidade tríplice, qual seja, o pleno desenvolvimento do educando, seu preparo para o exercício da cidadania e sua qualificação para o trabalho. No pleno desenvolvimento humano está a

\footnotetext{
${ }^{13}$ Em outras palavras: dignidade da pessoa humana.
} 
contribuição para o desenvolvimento psicológico do educando de forma progressiva e harmoniosa, no nível cognitivo onde "as pessoas desenvolvem a aprendizagem na relação direta com o seu mundo e, também, no uso do vocabulário, à medida que as palavras são portadoras de sentido" (CARNEIRO, 2013, p. 43). Na finalidade ligada ao preparo do exercício da cidadania, deve-se rememorar o conceito de cidadão como sujeito titular de direitos e deveres. Sendo que a educação é o primeiro direito social elencado pela Constituição. Em relação à terceira finalidade, Carneiro leciona a "relação educação-trabalho deve ser entendida como a necessidade de fazer do trabalho socialmente produtivo um elemento gerador de dinâmica escolar [...] a educação deve ser concebida como um processo onde ciência e trabalho coincidem" (CARNEIRO, 2013, p. 48).

O ECA também estabelece o direito/dever educação em seu artigo $4^{\circ}$, salientando o dever de todos, com prioridade absoluto, inclusive no que concerne aos recursos públicos (BRASIL, 1990).

Ora, a legislação prevê absoluta prioridade aos direitos da criança e ao adolescente e, entre os direitos elencados, está o da educação. Reforçando o argumento, o parágrafo único coloca a necessidade preferencial das políticas públicas à crianças e adolescentes, bem como a destinação privilegiada de recursos para a proteção da criança e do adolescente.

Desta forma, é importante destacar que existe latente omissão por parte do Estado no que concerne à políticas públicas e destinação de recursos para a área da educação (FRAGA, 2018).

Poder-se-ia questionar o porquê da insistência no caráter educacional, sendo que existem outros direitos fundamentais previstos. Sobrevém que a educação é base para a dignidade da pessoa humana e para a construção da própria cidadania. Crianças, adolescentes, jovens, adultos e idosos bem educados conseguem a exata compreensão do que é ser cidadão, pessoa de direitos e obrigações.

O Estado desrespeita a legislação. Assim está positivado no artigo $5^{\circ}$ do ECA: "Nenhuma criança ou adolescente será objeto de qualquer forma de negligência, discriminação, exploração, violência, crueldade e opressão, 
punido na forma da lei qualquer atentado, por ação ou omissão, aos seus direitos fundamentais". (Grifo nosso)

O Estado deve ser responsabilizado por sua omissão diante da qualidade de educação que oferece (TOKARNIA, 2018). Existem milhares de crianças que andam distâncias quilométricas (ATHIAS) para ter acesso à uma escola e, lá chegando, além da educação abaixo dos padrões necessários a uma formação adequada, não têm respeitados seus direitos fundamentais de dignidade. Atente-se para a previsão do artigo $7^{\circ}$ do ECA: "A criança e o adolescente têm direito a proteção à vida e à saúde, mediante a efetivação de políticas sociais públicas que permitam o nascimento e o desenvolvimento sadio e harmonioso, em condições dignas de existência”. (Grifo nosso)

Onde encontram-se as condições dignas de existência previstas para estes que são o futuro do Brasil? Elas não existem, pois o orçamento, onde se estabeleceria a prioridade de investimento sofre os danos imensuráveis da corrupção que assola a classe política brasileira. Não existe absoluta prioridade quando o aparelho estatal ,o instrumento de quem tem o dever de assegurar a prioridade da educação, é usado em prol do interesse de uma casta dos que se se elegem como representantes do povo e atuam em benefício próprio.

Atesta-se tal indignação quando a Lei $\mathrm{n}^{0}$ 10.172/2001 - Plano Nacional de Educação - sintetiza seus objetivos nos seguintes termos:

\section{OBJETIVOS E PRIORIDADES}

Em síntese, o Plano tem como objetivos:

. a elevação global do nível de escolaridade da população;

. a melhoria da qualidade do ensino em todos os níveis;

- a redução das desigualdades sociais e regionais no tocante ao acesso e à permanência, com sucesso, na educação pública $\mathrm{e}$

- democratização da gestão do ensino público, nos estabelecimentos oficiais, obedecendo aos princípios da participação dos profissionais da educação na elaboração do 
projeto pedagógico da escola e a participação das comunidades escolar e local em conselhos escolares ou equivalentes.

Considerando que os recursos financeiros são limitados e que a capacidade para responder ao desafio de oferecer uma educação compatível, na extensão e na qualidade, à dos países desenvolvidos precisa ser construída constante e progressivamente, são estabelecidas prioridades neste plano, segundo o dever constitucional e as necessidades sociais. (BRASIL, 2001) (Grifo nosso)

Não se acredita tratar-se de recursos financeiros limitados, mas de má gestão do Poder Executivo, com o desvio de verbas - inclusive da verba de merenda escolar -; trata-se da morosidade do Legislativo em colocar em pauta temas voltados para a educação, afinal, a prioridade tem sido o aumento dos próprios salários e de seus privilégios.

O Plano ainda trata das várias modalidades de educação, quais sejam, educação infantil, ensino fundamental, ensino médio, educação de jovens e adultos, educação especial, educação à distância e tecnologias educacionais, educação superior, educação indígena etc. Mais adiante prevê "a formação dos professores e valorização do magistério" que, na teoria, deve ser valorizado com a formação de profissionais, salários dignos (BRASIL, 2001).

A realidade demonstra que além da péssima infraestrutura dos estabelecimentos de ensino; os professores não recebem um salário digno com seu ofício (BRASIL, 2003). Pois como o próprio plano atesta há grande abandono por parte do professores devido às condições precárias de trabalho e salários que não condizem com o ofício. Os professores, como qualquer profissional, possuem anseios e desejam crescimento no seu ofício. A educação diante do mundo globalizado exige a qualificação e o aperfeiçoamento dos profissionais em seus diversos níveis ${ }^{14}$.

\footnotetext{
14 "Ano após ano, grande número de professores abandona o magistério devido aos baixos salários e às condições de trabalho nas escolas. Formar mais e melhor os profissionais do magistério é apenas uma parte da tarefa. É preciso criar condições que mantenham o entusiasmo inicial, a dedicação e a confiança nos resultados do trabalho pedagógico. É preciso que os professores possam vislumbrar perspectivas de
} 
Ressalte-se que referido Plano, criado pela Lei 10.172 foi promulgado em 9 de janeiro de 2001 após 18 anos quase nada ou nada foi feito para a concreção do direito fundamental à educação. E sem educação não há dignidade humana, não há cidadania.

Não menos importante, o direito do idoso à educação, estabelecido pelo Estatuto do Idoso, em seu artigo 20. Impõe-se, nesse diploma ao Poder Público, o dever de concretizar tal garantia, conforme previsto no artigo 21: “o Poder Público criará oportunidades de acesso do idoso à educação, adequando currículos, metodologias e material didático aos programas educacionais a ele destinados" (BRASIL, 2003)

Diante da ausência de prestação estatal, devido à inércia do Poder Executivo e do descaso do Poder Legislativo, resta ao cidadão, com fundamento no artigo $5^{\circ}$, inciso XXXV, provocar o Poder Judiciário para a tomada de providências necessárias que assegurem a concreção do direito fundamental à educação, como base para a construção da cidadania e da consciência de dignidade humana. Fundamenta-se a pretensão na ideia de estado de coisas inconstitucional, posicionamento novo no Supremo Tribunal Federal, como instrumento de garantia diante da grave violação do direito social fundamental à educação.

\section{Estado de coisas inconstitucional (ECI)}

O denominado estado de coisas inconstitucional é uma linha de argumentação que surgiu na Colômbia diante de uma falha estrutural e sistêmica dos Poderes Executivo e Legislativo. Na época, foi invocado diante do desrespeito estrutural e generalizado dos direitos

crescimento profissional e de continuidade de seu processo de formação. Se, de um lado, há que se repensar a própria formação, em vista dos desafios presentes e das novas exigências no campo da educação, que exige profissionais cada vez mais qualificados e permanentemente atualizados, desde a educação infantil até a educação superior (e isso não é uma questão meramente técnica de oferta de maior número de cursos de formação inicial e de cursos de qualificação em serviço) por outro lado é fundamental manter na rede de ensino e com perspectivas de aperfeiçoamento constante os bons profissionais do magistério. Salário digno e carreira de magistério entram, aqui, como componentes essenciais. Avaliação de desempenho também tem importância, nesse contexto". (Grifo nosso). 
previdenciários. Posteriormente, foi adotado diante da situação caótica na qual se encontrava o sistema prisional colombiano.

A Corte Colombiana fundamentou o estado de coisas inconstitucional no dever do Poder Judiciário, em especial a "Suprema Corte", em harmonia com os outros Poderes, de garantir a eficácia da Constituição no combate àquilo que a viola, evitando, dessa forma, a judicialização de situações semelhantes. Dessa maneira se manifestou a Corte Colombiana em 1997:

O Tribunal Constitucional tem o dever de colaborar harmonicamente com os demais órgãos do Estado para a realização de seus fins. Do mesmo modo, deve comunicar à Autoridade competente a notícia relativa à prática de um crime, pois não se deve omitir a notificação diante de um estado de coisas que viola a Constituição. $\mathrm{O}$ dever de cooperação torna-se imperativo se é o remédio administrativo adequado para evitar o uso excessivo de ações de tutela. Os recursos disponíveis para a administração da justiça são escassos. Se suscitar o cumprimento diligente das obrigações constitucionais à uma autoridade ajudar a reduzir o número de casos constitucionais, que, de outra forma, inevitavelmente, seriam apresentados, tal ação é meio legítimo para que o Tribunal exerça a sua função de guardião da integridade da Constituição e da eficácia de seus mandamentos. Se o estado de coisas, como tal, não é consistente com a Constituição, está diretamente relacionada com a violação dos direitos fundamentais, verificada em um processo de proteção por parte do Tribunal Constitucional, a notificação de regularidade existente pode ser acompanhado por uma exigência específica ou genérica dirigidas às autoridades no sentido de realizar uma ação ou de se abster de fazê-lo. Neste caso, deve ser entendido que a notificação e o requerimento compõem o repertório de comandos que podem levar o Tribunal, em sede de revisão, a fim de restaurar a ordem fundamental transgredida. $\mathrm{O}$ fato de que a situação não só serve para apoiar o causas de lesão ao direito fundamental examinado, mas também, se refere a situações semelhantes, não podendo se restringir o alcance do pedido formulado. (Tradução livre). ${ }^{15} 16$

15 Sentencia SU.559/97. Disponível em: http://www.corteconstitucional.gov.co/relatoria/1997/SU55997.htm. Acesso em 26 de set. 2020. 
De modo semelhante a Corte Colombiana se manifestou no ano seguinte afirmando a figura do estado de coisas inconstitucional como forma de solucionar a violação estrutural dos direitos fundamentais da coletividade. ${ }^{17} 18$

Como se pode verificar do posicionamento da Suprema Corte Colombiana, estado de coisas inconstitucional tem o objetivo de superar situações estruturais que violam os direitos fundamentais, notificando a quem compete a solução do evidente descompasso constitucional. Porém, a decretação do ECI, embora para alguns seja ativismo judicial, deve ser vista como medida excepcional adotada ante a insensatez e falta de responsabilidade do Poder Público para com a população.

De acordo com Campos, a declaração do estado de coisas inconstitucional ocorre diante de um quadro extremo de violação dos direitos fundamentais, razão pela qual a Corte Suprema, como guardiã da constituição deve atuar como implementadora de políticas públicas que para

\footnotetext{
${ }^{16}$ La Corte Constitucional tiene el deber de colaborar de manera armónica con los restantes órganos del Estado para la realización de sus fines. Del mismo modo que debe comunicarse a la autoridade competente la noticia relativa a la comisión de un delito, no se ve por qué deba omitirse la notificación de que un determinado estado de cosas resulta violatorio de la Constitución Política. El deber de colaboración se torna imperativo si el remedio administrativo oportuno puede evitar la excesiva utilización de la acción de tutela. Los recursos con que cuenta la administración de justicia son escasos. Si instar al cumplimiento diligente de las obligaciones constitucionales que pesan sobre una determinada autoridad contribuye a reducir el número de causas constitucionales, que de otro modo inexorablemente se presentarían, dicha acción se erige también em medio legítimo a través del cual la Corte realiza su función de guardiana de la integridad de la Constitución y de la efectividad de sus mandatos. Si el estado de cosas que como tal no se compadece con la Constitución Política, tiene relación directa con la violación de derechos fundamentales, verificada en un proceso de tutela por parte de la Corte Constitucional, a la notificación de la regularidade existente podrá acompañarse un requerimiento específico o genérico dirigido a las autoridades en el sentido de realizar una acción o de abstenerse de hacerlo. En este evento, cabe entender que la notificación y el requerimiento conforman el repertorio de órdenes que puede librar la Corte, en sede de revisión, con el objeto de restablecer el orden fundamental quebrantado. La circunstancia de que el estado de cosas no solamente sirva de soporte causal de la lesión iusfundamental examinada, sino que, además, lo sea en relación con situaciones semejantes, no puede restringir el alcance del requerimiento que se formule.

17 Sentencia T-153/98. Disponível em: http://www.corteconstitucional.gov.co/relatoria/1998/T-15398.htm. Acesso em 26 de set. de 2020 .

${ }^{18}$ En las sentencias SU-559 de 1997 y T-068 de 1998 esta Corporación ha hecho uso de la figura del estado de cosas inconstitucional con el fin de buscar remedio a situaciones de vulneración de los derechos fundamentales que tengan un carácter general - en tanto que afectan a multitud de personas -, y cuyas causas sean de naturaleza estructural - es decir que, por lo regular, no se originan de manera exclusiva en la autoridad demandada y, por lo tanto, su solución exige la acción mancomunada de distintas entidades. En estas condiciones, la Corte ha considerado que dado que miles de personas se encuentran en igual situación y que si todas acudieran a la tutela podrían congestionar de manera innecesaria la administración de justicia, lo más indicado es dictar órdenes a las instituciones oficiales competentes con el fin de que pongan en acción sus facultades para eliminar ese estado de cosas inconstitucional.
} 
superar a situação (CAMPOS, 2015). Prova que se trata de medida adotada em excepcional gravidade é que para a decretação do ECI, Ramos afirma que se faz necessário um quadro: “(i) generalizado e (ii) longevo de violações de direitos, que se mostra imune a mudanças, graças à (iii) constante ineficiência (por ações ou omissões) dos agentes políticos eleitos (de diferentes partidos)”. (RAMOS, 2018, p. 810).

Não se trata do direito de um único indivíduo, mas do desrespeito generalizado de direitos ante a ineficácia, insensibilidade e omissão daqueles que, em tese, deveriam defender os interesses do povo. Ao reconhecer o ECI, o Judiciário pode adotar medidas que façam o Poder Público se movimentar para a concreção dos direitos. Tal instrumento não é uma ofensa ao artigo $2^{\circ}$ da Constituição Federal que rege a separação dos poderes. Mas é meio eficaz para provocar os outros dois Poderes que não devem e não podem ser inertes. "Esse tipo de conduta do Poder Judiciário não visa satisfazer o direito de vítimas individualizadas, mas sim gerenciar o cumprimento dos deveres de proteção do Estado em relação a todos os afetados, até que a situação seja revertida" (RAMOS, 2018, p. 810).

Como o próprio nome do instituto diz: é um estado e como tal, diante da situação inconstitucional que lhe acomete, deve ser superado para outro estado: o da constitucionalidade. No Brasil, o instituto do ECI é recente, inserido mais precisamente no ano de 2015 e previsto, pela primeira vez, na ADPF $n^{\circ}$. 347, ajuizada pelo PSOL, que pleiteava ao STF o reconhecimento do estado de coisa inconstitucional junto ao sistema penitenciário pátrio, ante a gravidade das condutas comissivas e omissivas do Poder Público que descumpriam os preceitos fundamentais constitucionais.

Não é necessário adentrar a fundo na questão da ADPF mencionada, pois segundo dados trazidos pela mídia e pela própria ementa do julgamento a crise do sistema carcerário pátrio é uma das maiores do mundo, haja vista a superlotação, condição estrutural e degradante (CABRAL, 2019) (BRASIL, 2016).

O reconhecimento do ECI pode ser uma proposta de diálogo não só entre os Poderes, mas também, entre o povo que, por meio do judiciário, 
pede a concreção de seus direitos. No que concerne ao direito social fundamental à educação, a decretação do ECI seria instrumento para a concreção de tal direito. O fato é que a educação é a base da sociedade e da própria cidadania. Além da previsão constitucional, o direito fundamental à educação tem ampla legislação que a tutela. Como noticiado pela imprensa, a situação da educação do país está em declínio.

De acordo com reportagem de Guilherme Balza (2018) entre os anos de 2015-2018, 9.300 salas de aula foram fechadas. Alunos e professores protestaram com aquilo que o Governo denominou reorganização escolar. Entrevistado por Balza, o professor de Artes Pedro Braga diz que isso acaba expondo o professor. "Você fecha as salas, e aumenta o número de alunos por sala de aula. Isso é pra não contratar mais funcionários. Aí tem o número excessivo de alunos por sala de aula, que nos torna mais expostos ainda a situações de indisciplina e violência".

A problemática se torna ainda maior quando se verifica a infraestrutura e constata-se que a maior parte das escolas não possui laboratório de ciências, sala de vídeo, sequer refeitório. Muitas escolas não possuem sala de leitura ou biblioteca. E para espanto maior, segundo a citada reportagem, 90\% das escolas não têm auto de vistoria dos bombeiros. Além de existirem aquelas que estão repletas de infiltrações, alagamentos e buracos. À época, o então presidente da APEOESP, Fábio Santos de Moraes afirmou à imprensa que as escolas estão completamente defasadas (BALZA, 2018).

Outro fato alarmante é a afirmação de professores que utilizam do próprio salário para comprar materiais voltados ao ensino. Segundo Gabriel Freitas, professor de Geografia de uma escola estadual da zona sul de São Paulo, verba para xerox de materiais para os alunos é bancada por ele (BALZA, 2018).

Quer nos parecer que problemática do corte de verbas voltadas para a educação não é de caráter econômico mas estrutural ante a omissão Pública. É hipocrisia afirmar que tal corte é devido à crise econômica que assola o 
país. Há uma crise evidente fruto da corrupção, do desvio e do enriquecimento ilícito de vários agentes públicos.

A Secretaria de Educação do Estado de São Paulo, ao responder as acusações da citada reportagem (BALZA, 2018), informou que o relatório do Tribunal de contas abrange somente a 1,7\% da escolas do estado, além de afirmar que até 2030 a regularização de questões básicas, como o Auto de Vistoria do Corpo de Bombeiros, estaria em ordem.

A situação é grave. O Estado demonstra o total desinteresse para com o direito fundamental social da educação. Afirmar que serão necessários doze anos para resolver o que é essencial para o funcionamento de um estabelecimento de ensino é não se importar com a segurança de alunos, professores. Conforme pode-se verificar a partir de informação contida no site dos Bombeiros ${ }^{19}$.

Não bastasse a falta de infraestrutura, o ensino de discutível qualidade, a desvalorização dos professores que não recebem salários dignos ao ofício que exercem impõe-se viver na insegurança de não ter as condições mínimas estabelecidas pelo próprio Estado.

Assim, denota-se que com a banalização do direito social fundamental à educação, nosso Estado Democrático de Direito encontrase defasado, banalizado, degradado, indigno, antidemocrático, injusto e insustentável de forma generalizada, constituindo-se no seu âmbito um status de estado de coisas inconstitucional. Isso se deve à inércia e irresponsabilidade do poder público. São necessárias medidas que contribuam para a concreção e efetivação do direito social à educação, contribuindo-se para a formação de cidadãos educados, informados e conscientizados de sua dignidade, dos seus direitos e deveres.

\footnotetext{
${ }^{19}$ Auto de Vistoria do Corpo de Bombeiros (A. V. C. B.), é o documento emitido pelo Corpo de Bombeiros da Policia Militar do Estado de São Paulo (CBPMESP) certificando que, durante a vistoria, a edificação possuía as condições de segurança contra incêndio (É um conjunto de medidas estruturais, técnicas e organizacionais integradas para garantir a edificação um nível ótimo de proteção no segmento de segurança contra incêndios e pânico.), previstas pela legislação e constantes no processo, estabelecendo um período de revalidação. Cf. em: https://www.bombeiros.com.br/avcb-clcb. Acesso em 27 de set. de /2020.
} 


\section{Conclusão}

O direito social fundamental à educação é base para a construção da cidadania e da dignidade da pessoa humana, ambos pilares do Estado Democrático de Direito.

Ser cidadão é muito mais que ser eleitor. O cidadão é aquele que participa de forma ativa na sociedade. $\mathrm{O}$ cidadão é o sujeito convocado a construir o sistema político em que o país se encontra. A cidadania é a concreção da efetiva democracia. Sem cidadania não existe democracia. A cidadania é o constante "grito" que emana do povo que clama por "Diretas Já!". Esse é o real sentido da democracia: poder que emana do povo que participa diretamente da vida política do país. Na qualidade de cidadão, o indivíduo exerce seu conjunto de direitos e deveres. A cidadania deve ser consciente para que o indivíduo e a própria sociedade não tenham seus direitos violados.

Mas quem é o cidadão; senão a pessoa dotada de dignidade? Assim, em consonância com a cidadania está a ideia de direitos humanos que pressupõe direitos inerentes à sua própria condição de pessoa, dando ênfase à sua particular dignidade. Desta forma, os direitos humanos e a dignidade da pessoa humana são princípios de natureza universal que não fazem acepção de indivíduos. A dignidade da pessoa humana é o encontro do cidadão humano com o outro que lhe é semelhante, mas, também, é o encontro de cada ser humano consigo mesmo, que reconhece seu valor, ou seja, a sua própria dignidade.

Ocorre que os direitos fundamentais possuem características próprias, dentre as quais se destacou a efetividade. Pois esta é um dever que o Estado impõe a si mesmo e que os cidadãos, dotados de dignidade, têm direito perante ao Poder Público. Na esteia da efetividade, criticou-se a ausência de uma educação efetiva e digna.

Embora a educação seja elencada como primeiro direito social na Carta Magna e sirva de base para a construção de uma sociedade democrática, pois é (a educação) o processo formativo pelo qual perpassa a 
dignidade da pessoa humana e a cidadania, verifica-se a omissão do Estado no que concerne à políticas públicas e destinação de recursos para a mesma.

A insistência no caráter educacional, apesar da existência de outros direitos fundamentais, é por compreender a educação como base para a dignidade da pessoa humana e para a construção da própria cidadania. Pessoas bem educadas contribuem, de forma ímpar, para a concreção dos outros direitos fundamentais, pois apreenderam o seu papel no mundo.

A evidente omissão Estado, frente ao que o mesmo propõe, causa uma pandemia em nosso país. Sem educação não há dignidade humana, não há cidadania. Frise-se que não é ausência de legislação, de previsão, mas a realidade de um Estado apático para com seu povo. Assim, diante da ausência de prestação estatal, devido à falta de efetividade dos Poder Executivo e Legislativo, resta ao cidadão provocar o Poder Judiciário para a tomada de providências necessárias que assegurem a concreção do direito fundamental à educação, como base para a construção da cidadania e da consciência de dignidade humana.

Para tanto, apesar de ser um posicionamento novo no Supremo Tribunal Federal, abordou-se o estado de coisas inconstitucional como instrumento de garantia diante da grave violação do direito social fundamental à educação. Não se trata aqui de uma invasão do Poder Judiciário ou mesmo numa sobreposição deste em relação ao outro dois Poderes., mas de reconhecer que nas suas funções jurídica e política de guardião da Constituição cabe Supremo Tribunal Federal, preservar as garantias constitucionais.

A realidade do estado de coisas inconstitucional referente ao direito social fundamental à educação é mais um dos frutos da corrupção. E referese à educação em sentido lato, pois a inconstitucionalidade encontra-se na falta de estruturas dignas, na qualidade, na remuneração irrisória recebida pelos professores, na ausência de acesso às tecnologias mais básicas. E se não for o guardião da Constituição a exigir a concreção dos direitos fundamentais, quem estará legitimado? 
Sem dúvida: o povo. Apesar da grande valia da teoria da tripartição dos poderes (funções) de Montesquieu na organização do Estado ela não suplanta o poder popular. Ela tão somente distribui funções aos representantes do poder. O equívoco da classe política brasileira é o esquecimento de quem é o verdadeiro poder em uma democracia. A democracia é o poder que emana do povo, ou seja, é do povo o poder. O Executivo, o Legislativo e o Judiciário apenas realizam as funções do poder a serviço deste povo. Porém, os representantes políticos em grande número e de modo geral, agem como se fossem donos do poder, como se os cargos que ocupam fossem para proveito pessoal. Ora, isso não é democracia, mas a usurpação de poder por uma classe cada vez mais desacreditada.

Por fim, é o povo, através do poder que lhe é próprio, que pleiteia o serviço do Judiciário para que, declarado eventual estado de coisas inconstitucional, a educação possa ocupar o seu devido lugar e, consequentemente, concretizar o sonho de um verdadeiro Estado Social Democrático de Direito. Não é necessário a criação de mais leis, a necessidade é dar a elas a concretude que se espera.

\section{Referências}

ABBAGNANO, N. Dicionário de Filosofia. Tradução de Alfredo Bosi e Ivone Castilho Benedetti. 5 ed. São Paulo: Martins Fontes, 2007.

ARISTÓTELES. Ética a Nicômaco. Tradução de Leonel Vallandro e Gerd Bornheim. In: Os Pensadores. São Paulo: Abril Cultural, 1979.

ATHIAS, Gabriela. Crianças andam $10 \mathrm{~km}$ para ir à escola. Disponível em: https://www1.folha.uol.com.br/fsp/cotidian/ff1903200003.htm.

Acesso em 16 de jan. 2020.

ATHIAS, Gabriela. Política. Tradução Julian Marias y Maria Araújo, edicion bilíngue, Madrid, 1951.

BALZA, Guilherme. O Estado de São Paulo fecha sete salas de aula por dia. Disponível em: https://cbn.globoradio.globo.com/media/audio/203649/estado-desao-paulo-fecha-sete-salas-de-aula-por-d.htm. Acesso em 27 de fev. de 2019. 
BRASIL. Constituição da República Federativa do Brasil. Promulgada em 5 de outubro de 1988.

BRASIL. Lei de Diretrizes e Bases da Educação Nacional. Lei nº 9.394/96.

BRASIL. Estatuto da Criança e do Adolescente. Lei nº 8.069/90.

BRASIL. Plano Nacional de Educação. Lei nº 10.172/2001.

BRASIL. Estatuto do Idoso. Lei n 10.741/2003.

BRASIL. Estudo mostra situação do professor brasileiro. Disponível em: http://portal.inep.gov.br/artigo/-

lasset publisher/B4AQV9zFY7Bv/content/estudo-mostra-situacao-doprofessor-brasileiro/21206. Acesso em 16 de set. 2020.

BRASIL. A Constituição e o Supremo. Disponível em http://www.stf.jus.br/portal/constituicao/artigoBd.asp?item=31. Acesso em 16 de set. 2020 .

CABRAL, Thiago. Estado de Coisas Inconstitucional: análise do julgamento da ADPF 347. Disponível em: https:/canalcienciascriminais.com.br/analisedo-julgamento-da-adpf-347/. Acesso em 16 de set. 2020.

CAMPOS, Carlos Alexandre de Azevedo. O estado de coisas inconstitucional e o litígio estrutural. Revista Consultor Jurídico, $1^{\circ}$ set. 2015. Disponível em: http://www.conjur.com.br/2015-set-01/ carlos-campos-estado-coisasinconstitucional-litigio-estrutural\#_ftn3. Acesso em: 26 set. de 2020.

CARNEIRO, Moaci Alves. LDB fácil: leitura crítico -compreensiva, artigo a artigo. 21 ed. Petrópolis, RJ: Vozes, 2013.

COLÔMBIA. Corte Constitucional República de Colombia. Sentencia SU.559/97. Disponível em:

http://www.corteconstitucional.gov.co/relatoria/1997/SU559-97.htm. Acesso em 26 de set. de 2020.

COLÔMBIA. Corte Constitucional República de Colombia. Sentencia T153/98. Disponível em http://www.corteconstitucional.gov.co/relatoria/1998/T-153-98.htm. Acesso em 26 de set. 2020.

COMPARATO, Fábio Konder. A afirmação histórica dos direitos humanos. 71 ed. Rev. e atual. São Paulo: Saraiva, 2010. 
CUNHA, Luís Antônio; XAVIER, Libânia. Lei de Diretrizes e Bases da Educação Nacional. Disponível em:

http://www.fgv.br/CPDOC/BUSCA/dicionarios/verbete-tematico/lei-dediretrizes-e-bases-da-educacao-nacional-ldben. Acesso em: 22 ago. de 2020.

EDITORIAL HUMANISTA. Balbúrdia é não investir em educação.

Disponível em: https://www.ufrgs.br/humanista/2019/05/15/editorial-ibalburdia-e-nao-investir-em-educacao/. Acesso em 16 ago. 2020.

DECLARAÇÃO UNIVERSAL DOS DIREITOS HUMANOS. Assembleia Geral das Nações Unidas em Paris. 10 dezembro de 1948. Disponível em: https://nacoesunidas.org/wp-content/uploads/2018/10/DUDH.pdf. Acesso em: 21 de fev. de 2020 .

DIEHL, Rafael Mesquita. Teologia Católica e Direitos Humanos. Curitiba: InterSaberes, 2018.

DUARTE, Clarice Seixas. A educação como um direito fundamental de natureza social. Educ. Soc., Campinas, vol. 28, n. 100 - Especial, p. 691-713, out. 2007. Disponível em: http://www.cedes.unicamp.br. Acesso em: 22 de fev. de 2019.

FRAGA, Érica. Investimento em educação no Brasil é baixo e ineficiente. Disponível em:

https://www1.folha.uol.com.br/educacao/2018/02/investimento-em-educacaono-brasil-e-baixo-e-ineficiente.shtml. Aceso em 16 de set. 2020.

HABERMAS, Jürgen. Direito e Democracia: entre facticidade e validade. Rio de Janeiro: Tempo Brasileiro, 2003, p. 354.

MASSON, Nathalia. Manual de direito constitucional. $3^{\mathrm{a}}$ ed. Revista, ampliada e atualizada.Salvador: Juspodivm, 2015,

MASTRODI, Josué; AVELAR, Ana Emília Cunha. O conceito de cidadania a partir da obra de T. H. Marshall: conquista e concessão. Cadernos de Direito, Piracicaba, v. 17(33): 3-27, jul-dez. 2017. ISSN Eletrônico: 22381228. Disponível em:

https://www.metodista.br/revistas/revistasunimep/index.php/cd/article/view File/3451/2072. Acesso em 25 de set. 2020.

MARSHALL, T. H. Cidadania e Classe Social [Ed. atual trad. e rev. Por EaD/CEE/MCT], 2. ed. Brasília: Senado Federal, Centro de Estudos Estratégicos, Ministério da Ciência e Tecnologia, 2002.

MORAES, Alexandre de. Direito Constitucional. 29 ed. São Paulo: Atlas, 2013. 
MOURA, Aline Beltrame. O discurso da cidadania em Marshall: a influência do modelo clássico na teoria jurídica moderna. JURISVOX. Patos de Minas: UNIPAM, (10):22-34, 2010. Disponível em: http://jurisvox.unipam.edu.br/documents/48188/50566/O-discurso-dacidadania-em-Marshall.pdf. Acesso em 22 mai. de 2020.

PARANÁ (Estado Brasileiro). Secretaria da Justiça, Trabalho e Direitos Humanos - Departamento de Direitos Humanos e Cidadania (DEDIHC) do Paraná. Disponível em:

http://www.dedihc.pr.gov.br/modules/conteudo/conteudo.php?conteudo=8. Acesso em 21 jul. de 2020.

PENTEADO FILHO, Nestor Sampaio. Direitos Humanos, 13. 3 ed. São Paulo: Saraiva, 2012.

RAMOS, André de Carvalho. Curso de direitos humanos. 5. ed. São Paulo: Saraiva Educação, 2018. (Livro digital (E-pub) Produção do e-pub Guilherme Henrique Martins Salvador)

REALE, Giovani; ANTISERI, Dario. História da Filosofia: Filosofia pagã antiga. v. 1. São Paulo: Paulus, 2003.

TOKARNIA, Mariana. MEC divulga nesta segunda indice de qualidade do ensino básico. Disponível em:

http://agenciabrasil.ebc.com.br/educacao/noticia/2018-09/mec-divulga-nestasegunda-indice-de-qualidade-do-ensino-basico. Acesso em 16 de jan. 2020.

TRINDADE JÚNIOR, Wanderley Baptista da. Direito Penitenciário Constitucional. Dissertação (mestrado) - Universidade de Ribeirão Preto, UNAERP, Direitos. Ribeirão Preto, 2015. 